\title{
Pricing Foreign Currency and Cross-Currency Options Under GARCH
}

\author{
Jin-Chuan Duan \\ Department of Finance \\ Hong Kong University of Science and Technology \\ Clear Water Bay, Kowloon \\ Hong Kong \\ Phone: (852) 23587671 \\ E-mail: jcduan@usthk.ust.hk
}

\author{
Jason Z. Wei \\ Faculty of Management \\ University of Toronto \\ 105 St. George Street \\ Canada, Ontario, Canada \\ M5S 3E6 \\ Phone: (416) 978-3698 \\ E-mail:wei@mgmt.utoronto.ca \\ First Draft August 1995 \\ Current Draft: April 1999
}

Jin Duan acknowledges the support received as Senior Wei Lun Fellow at the Hong Kong University of Science and Technology. Jason Wei acknowledges financial support by the Social Sciences and Humanities Research Council of Canada and the University of Toronto Connaught Fund. Both authors wish to thank an anonymous referee and the Editor for useful suggestions and comments. 


\title{
Pricing Foreign Currency and Cross-Currency Options Under GARCH
}

\begin{abstract}
The main objective of this paper is to propose an alternative valuation framework for pricing foreign currency and cross-currency options, which is capable of accommodating existing empirical regularities. The paper generalizes the GARCH option pricing methodology of Duan (1995) to a twocountry setting. Specifically, we assume a bivariate nonlinear GARCH system for the exchange rate and the foreign asset price, and generalize the local risk-neutral valuation principle for pricing derivatives. We define an equilibrium price measure in the two-country economy and derive the locally risk-neutralized GARCH processes for the exchange rate and the foreign asset price. Foreign currency options and cross-currency options are then valued using Monte Carlo simulations. Our setup accommodates rich empirical regularities such as stochastic volatility, fat tailed distributions and leverage effect extensively documented for financial data series. Numerical results show that our proposed model exhibits properties that are consistent with the documented empirical regularities for foreign currency options and quanto options.
\end{abstract}

\section{Introduction}

It has been well documented in the literature that stock returns possess such properties as leptokurtosis or "fat-tails" and time-varying variances [see, e.g., Black (1976)]. The first successful attempt to econometrically model these properties was by Engle (1982) who introduced the Autoregressive Conditional Heteroscedasticity $(\mathrm{ARCH})$ model. Extensions to this model were subsequently made by many researchers; for example, Bollerslev (1986) and Taylor (1986) proposed the generalized ARCH (GARCH) model, Nelson (1991) the exponential GARCH model, Engle and $\mathrm{Ng}$ (1993) the nonlinear asymmetric GARCH, among many others. The existence of a massive GARCH literature has prompted the review article like Bollerslev, et al (1992) and the work by Duan (1997) to encompass the existing GARCH models into a common system known as the augmented GARCH(p,q) process. Notwithstanding many variants of the GARCH model, it is generally found that a low-order GARCH model allowing for leverage effect is adequate for characterizing most financial series.

Researchers have recently started using the ARCH setup to examine market prices of options. Most studies, however, incorporated the time-varying volatility in an ad hoc fashion [see, for example, Engle and Mustafa (1992), Day and Lewis (1992), and Noh, Engle and Kane (1994), Engle and Rosenberg (1995)]. The theory for pricing options in the GARCH framework was first 
developed by Duan (1995) in an equilibrium framework. By introducing the locally risk-neutral valuation relationship (LRNVR), Duan (1995) derived an option pricing model which depends upon, among other factors, a risk premium parameter. The proposed model can explain many welldocumented option pricing biases. In a related study based on a relatively large scale of simulations, Chaudhury and Wei (1996) systematically compared Duan's GARCH option pricing model with the Black-Scholes model. Consistent with Duan's finding, Chaudhury and Wei found that the GARCH option pricing model is most useful when pricing short maturity, out-of-the-money options. On the empirical front, Amin and $\mathrm{Ng}$ (1993) have found a significantly better performance by the GARCH option pricing model in comparison to the Black and Scholes model. Heynen, Kemna and Vorst (1994) have shown that the "term structure of the implied volatilities" can be explained by the GARCH option pricing model. More recently, Duan (1996) was successful in using the GARCH option pricing model to simultaneously fit the "volatility smile" and the "term structure of implied volatilities".

To date, there has been no known literature which incorporates GARCH into the pricing of cross-currency options, or options on foreign assets. Existing studies on cross-currency options all assume lognormal asset prices and exchange rate with constant or time-deterministic volatilities [see, e.g., Wei (1992), Dravid, Richardson and Sun (1993), and Gruca and Ritchken (1993)]. Given the observed stock return properties mentioned earlier and the stylized facts of exchange rate movements such as leptokurtosis and volatility clustering, it is important that we build those features into the theoretical pricing models for foreign currency and cross-currency options. ${ }^{1}$

This paper generalizes the GARCH option pricing methodology to the cross-currency setting. Specifically, we model the foreign exchange rate and the foreign asset price as a bivariate nonlinear asymmetric GARCH process. We generalize the local risk-neutral valuation relationship in Duan (1995) and define an equilibrium price measure in a two-country economy. Equilibrium processes for the exchange rate and the foreign asset price are derived under this measure, and cross-currency options can then be valued using the well-known risk-neutral valuation technique. Naturally, this

\footnotetext{
1. In this paper, "cross-currency options" means options written on a foreign asset which are traded in domestic currency. Cross-currency options can be grouped into four categories according to the specification of payoff conversion. Consider European call options on a foreign stock. Let $S_{\mathrm{T}}$ and $\mathrm{e}_{\mathrm{T}}$ be the stock price and exchange rate at option's maturity, $\mathrm{e}_{0}$ a pre-specified, fixed exchange rate, and $\mathrm{K}$ the exercise price denominated in foreign currency. Then the four possible payoff specifications are: $\mathrm{e}_{\mathrm{T}} \max \left[0, \mathrm{~S}_{\mathrm{T}}-\mathrm{K}\right], \mathrm{e}_{0} \max \left[0, \mathrm{~S}_{\mathrm{T}}-\mathrm{K}\right], \max \left[0, \mathrm{e}_{0} \mathrm{~S}_{\mathrm{T}}-\mathrm{e}_{\mathrm{T}} \mathrm{K}\right]$, and $\max [0$, $\left.\mathrm{e}_{\mathrm{T}} \mathrm{S}_{\mathrm{T}}-\mathrm{e}_{0} \mathrm{~K}\right]$.
} 
paper also provides a framework to price foreign currency options under GARCH. The proposed pricing framework incorporates stochastic volatility, unconditional leptokurtosis or "fat tails", and a correlation between the lagged return and the conditional variance for both the exchange rate and the foreign stock price.

The remainder of the paper is organized as follows. Section 2 introduces the GARCH process for the foreign exchange rate and identifies the corresponding process under the equilibrium price measure. This establishes a pricing framework for foreign currency options. Section 3 expands the framework in Section 2 by introducing the GARCH process for the foreign asset price. Properties of the asset price under the equilibrium price measure are identified, and the procedure for valuing cross-currency options is outlined. In Section 4, we briefly surveys the empirical evidence in the foreign currency options markets and the cross-currency options market, and then perform simulation studies to show that our model is capable of accommodating most of the empirical regularities in option prices. The paper is concluded in Section 5.

\section{Foreign Exchange Options Valuation under GARCH}

Let $\mathrm{e}_{\mathrm{t}}$ denote the exchange rate between the domestic and foreign markets at time $\mathrm{t}$, defined as the domestic currency units per foreign currency unit. The dynamic of $\mathrm{e}_{\mathrm{t}}$ is governed by the probability law $\mathrm{P}$ with respect to an information filtration $\mathscr{F}_{t}$. This exchange rate is assumed to follow a nonlinear GARCH-mean model under P.

\section{Assumption 1}

$$
\begin{gathered}
\ln \frac{e_{t+1}}{e_{t}}=r_{d, t+1}-r_{f, t+1}+\delta_{t+1} \sqrt{q_{t+1}}-\frac{1}{2} q_{t+1}+\sqrt{q_{t+1}} \varepsilon_{t+1} \\
\varepsilon_{t+1} \mid \mathscr{F}_{t} \stackrel{P}{\sim} N(0,1)^{\sim} N \alpha_{t+1}=\alpha_{0}+\alpha_{1} q_{t}\left(\varepsilon_{t}-a\right)^{2}+\alpha_{2} q_{t} \\
\left(\alpha_{0}>0, \quad \alpha_{1} \geq 0, \quad \alpha_{2} \geq 0, \text { and } \alpha_{1}\left(1+a^{2}\right)+\alpha_{2}<1\right)
\end{gathered}
$$


where $r_{d, t+1}\left(r_{f, t+1}\right)$ denotes the one-period, continuously compounded domestic (foreign) riskfree interest rate from time $t$ to time $(t+1) ; \delta_{t+1}$ is the unit risk premium for the exchange rate; and $r_{d, t+1}$, $\mathrm{r}_{\mathrm{f}, \mathrm{t}+1}, \delta_{\mathrm{t}+1}$, and $\mathrm{q}_{\mathrm{t}+1}$ are $\mathscr{F}_{t}$-measurable (i.e., they are all known at time $\mathrm{t}$ ).

To facilitate option pricing we need to define an equilibrium price measure. Similar to Duan (1995), we adopt the following definition.

Definition An equilibrium price measure $\mathrm{Q}_{\mathrm{d}}$ for the domestic market is said to satisfy the local risk-neutral valuation relationship (LRNVR) if for any asset value (cum dividends, if any) measured in domestic currency, denoted by $\mathrm{X}_{\mathrm{d}, \mathrm{t}}$, the following conditions are satisfied:

(i) $\quad Q_{d}$ is mutually continuous with respect to $P$;

$$
\begin{aligned}
& \frac{X_{d, t+1}}{X_{d, t}} \text { is lognormally distributed under } \mathrm{Q}_{\mathrm{d}} \text {; } \\
& E^{Q_{d}}\left(\frac{X_{d, t+1}}{X_{d, t}} \mid \mathscr{F}_{t}\right)=\exp \left(r_{d, t+1}\right) \quad \text { almost surely under P; and } \\
& \operatorname{Var}^{Q_{d}}\left(\ln \frac{X_{d, t+1}}{X_{d, t}} \mid \mathscr{F}_{t}\right)=\operatorname{Var}^{P}\left(\ln \frac{X_{d, t+1}}{X_{d, t}} \mid \mathscr{F}_{t}\right) \quad \text { almost surely under P. }
\end{aligned}
$$

Remark A similar definition can be given for the foreign equilibrium price measure $\mathrm{Q}_{\mathrm{f}}$.

Detailed discussions on LRNVR in a single-economy setting are given in Duan (1995) who identifies forms of utility functions (for the representative agent) sufficient for the LRNVR. Here we generalize the definition to include foreign assets. As long as the foreign asset in question is measured in domestic currency the above definition applies. It is clear that the exchange rate is a special foreign asset denominated in domestic currency. ${ }^{2}$

For convenience and by convention, we work under the domestic equilibrium price measure $\mathrm{Q}_{\mathrm{d}}$. It can be shown that values of derivatives remain the same regardless of which measure we

2. It can be verified that the following conditions are sufficient for the generalized LRNVR to hold: A domestic representative agent maximizes expected (time separable and additive) utility with any of the following features: 1) utility is of CRRA and changes in the logarithm of aggregate consumption are conditionally normal under P; 2) utility is of CARA and changes in the aggregate consumption are conditionally normal under P; and 3) utility is linear. Notice that the first two moments governing the conditional distribution of the aggregate consumption dynamics can be stochastic unless constant interest rates are required. 
adopt. For pricing purposes we need to bring all variables from measure $\mathrm{P}$ to measure $\mathrm{Q}_{\mathrm{d}}$ so that risk-neutral discounting of expected payoffs can be applied. This is achieved in Proposition 1.

Proposition 1 Under Assumption 1, if the domestic equilibrium price measure $\mathrm{Q}_{\mathrm{d}}$ satisfies the LRNVR, then

$$
\ln \frac{e_{t+1}}{e_{t}}=r_{d, t+1}-r_{f, t+1}-\frac{1}{2} q_{t+1}+\sqrt{q_{t+1}} \varepsilon_{t+1}^{*},
$$

where

$$
\begin{gathered}
\varepsilon_{t+1}^{*}=\varepsilon_{t+1}+\delta_{t+1} \mid \mathscr{T}_{t} \stackrel{Q_{d}}{\sim} N(0,1), \\
q_{t+1}=\alpha_{0}+\alpha_{1} q_{t}\left(\varepsilon_{t}^{*}-\delta_{t}-a\right)^{2}+\alpha_{2} q_{t} .
\end{gathered}
$$

Proof: Similar to that in Duan (1995).

With (2) we can price European options on the exchange rate. For example, the value of a European call option at time $\mathrm{t}$ with an exercise price of $\mathrm{K}$ and time to maturity of $\mathrm{T}$ can be expressed as:

$$
C_{t}^{F X}=E^{Q_{d}}\left[\exp \left(-\sum_{s=t+1}^{T} r_{d, s}\right) \max \left(0, e_{T}-K\right) \mid \mathscr{F}_{t}\right]
$$

In our general setting there is no closed-form solution for (3). We must resort to simulations to recursively apply the dynamics in (2) for the generation of $e_{T}$.

Notice that if the two persistence parameters, $\alpha_{1}$ and $\alpha_{2}$, are set equal to zero, our pricing result simplifies to the one under homoscedastic exchange rate returns [see, e.g., Biger and Hull (1983), and Garman and Kohlgahen (1983)]. As mentioned earlier, our setup allows not only fat tails in returns, but also a correlation between the lagged exchange rate return and the conditional variance, both of which will affect the value of foreign currency options. 


\section{Cross-Currency Options Valuation under GARCH}

In this section we expand the theoretical framework in Section 2 to include a tradable foreign asset, a foreign stock. To this end, we assume that the foreign stock price also follows a nonlinear $\operatorname{GARCH}(1,1)$-mean process.

Assumption 2 The foreign stock price (cum dividends, if any) satisfies the following dynamic:

$$
\begin{gathered}
\ln \frac{S_{t+1}}{S_{t}}=r_{f, t+1}+\lambda_{t+1} \sqrt{h_{t+1}}-\frac{1}{2} h_{t+1}+\sqrt{h_{t+1}} \xi_{t+1} \\
\xi_{t+1} \mid \mathscr{F}_{t} \stackrel{P}{\sim} N(0,1) \\
h_{t+1}=\beta_{0}+\beta_{1} h_{t}\left(\xi_{t}-b\right)^{2}+\beta_{2} h_{t} \\
E^{P}\left(\varepsilon_{t+1} \xi_{t+1} \mid \mathscr{F}_{t}\right)=\rho_{t+1} \\
\left(\beta_{0}>0, \quad \beta_{1} \geq 0, \quad \beta_{2} \geq 0, \text { and } \beta_{1}\left(1+b^{2}\right)+\beta_{2}<1\right)
\end{gathered}
$$

where $r_{f, t+1}$ is defined in section 2 and $\lambda_{t+1}$ is the unit risk premium for the foreign stock price and is $\mathscr{T}_{t}$-measurable. $h_{t+1}$ is the conditional variance of the stock return and is also $\mathscr{F}_{t}$-measurable. Notice that we allow a stochastic $\left(\mathscr{F}_{t}\right.$-measurable) conditional correlation, $\rho_{t+1}$, between the stock return and the exchange rate return. The nonlinear GARCH specification of the stock price is motivated by the well-known "leverage effect" first discovered by Black (1976) and later substantiated by Christie (1982). The inclusion of parameter $b$ makes the stock return and volatility correlated. Specifically, a positive (negative) $b$ leads to a negative (positive) correlation.

As in Proposition 1 for the exchange rate process, we now identify the dynamic of the foreign stock price under the domestic equilibrium price measure $\mathrm{Q}_{\mathrm{d}}$.

Proposition 2 Under Assumptions 1 and 2, if $\mathrm{Q}_{\mathrm{d}}$ satisfies the LRNVR, then

$$
\ln \frac{S_{t+1}}{S_{t}}=r_{f, t+1}-\rho_{t+1} \sqrt{h_{t+1} q_{t+1}}-\frac{1}{2} h_{t+1}+\sqrt{h_{t+1}} \xi_{t+1}^{*}
$$

where 


$$
\begin{gathered}
\xi_{t+1}^{*}=\xi_{t+1}+\lambda_{t+1}+\rho_{t+1} \sqrt{q_{t+1}} \mid \mathscr{F}_{t} \underset{\sim}{Q_{d}} N(0,1), \\
h_{t+1}=\beta_{0}+\beta_{1} h_{t}\left(\xi_{t}^{*}-\lambda_{t}-\rho_{t} \sqrt{q_{t}}-b\right)^{2}+\beta_{2} h_{t}, \text { and } \\
E^{Q_{d}}\left(\varepsilon_{t+1}^{*} \xi_{t+1}^{*} \mid \mathscr{F}_{t}\right)=\rho_{t+1} .
\end{gathered}
$$

Proof: See Appendix.

Remark The dynamic of the foreign stock price under the foreign equilibrium price $\mathrm{Q}_{\mathrm{f}}$ is the same as that in Duan (1995) if $\mathrm{Q}_{\mathrm{f}}$ satisfies the LRNVR.

Several observations can be made about the above results. First, the conditional correlation between the exchange rate and the stock price remains the same under both measures, which greatly simplifies the valuation process since we can use observed data under measure $\mathrm{P}$ to estimate the correlation. Second, as in Duan (1995), the local risk-neutralization does not eliminate the unit risk premium parameter globally. The magnitude of the risk premium will affect the innovation of the conditional variance under $\mathrm{Q}_{\mathrm{d}}$, which in turn affects the prices of options written on the foreign stock. Third, the change of measure brings a conditional covariance term into the drift. This is equivalent to the drift adjustment in the Black-Scholes modelling framework used by Wei (1992) to identify the domestic risk-neutralized process of a foreign asset price. Fourth, when we set $\alpha_{1}$ and $\alpha_{2}$ in (1) and $\beta_{1}$ and $\beta_{2}$ in (4) equal to zero and the conditional correlation to a constant, the pricing framework specified in Proposition 1 and Proposition 2 reduces to the cross-currency option pricing framework of Wei (1992) and others.

With the systems in (2) and (5), we can value any European cross-currency options by discounting expected payoffs under measure $\mathrm{Q}_{\mathrm{d}}$. For instance, a quanto call, which is a call on a foreign stock with fixed exchange rate payoff conversion, can be valued as:

$$
C_{t}^{\text {quanto }}=e_{0} E^{Q_{d}}\left[\exp \left(-\sum_{s=t+1}^{T} r_{d, s}\right) \max \left(0, S_{T}-K\right) \mid \mathscr{F}_{t}\right]
$$

where $e_{0}$ is a pre-specified, fixed exchange rate, $\mathrm{K}$ is the exercise price denominated in foreign currency, T is the option's maturity, and $S_{T}$ is the stock price at time T. Since a closed-form solution 
to (6) is not available, we must resort to Monte Carlo simulations. It is interesting to note that even for a quanto option which involves only the foreign asset in the payoff function, we need to simulate the process in (2) jointly with that in (5). This is because the conditional mean and variance terms in (5) are time-varying and partly driven by the past random innovations in (2).

Although the domestic and foreign interest rates, the unit risk premia and the conditional correlation coefficient are allowed to be stochastic, implementing the pricing model will require specifying the processes for them. For simplicity, we assume in numerical analyses that they are constants. It should also be noted that the use of a bivariate $\operatorname{GARCH}(1,1)$ model is for illustration purposes, and the result can be straightforwardly generalized to any bivariate GARCH(p, q) model.

\section{Price Behaviour of FX Options and Quanto Options Under GARCH}

In this section we study price behaviour of foreign exchange options and quanto options under the GARCH specification. In order to standardize the option prices corresponding to different maturities and exercise prices, we follow the standard practice in option research to use the constant volatility closed-form option pricing formulas to calculate the Black-Scholes implied volatilities. The

primary goal is to determine whether our proposed GARCH pricing approach has the potential of accommodating the important empirical phenomenon - volatility smile - extensively documented for market option prices.

The two systems under the data generating probability measure P, i.e., (1) and (4), are jointly estimated using daily data for the Nikkei 225 index and the U.S. dollar/Yen exchange rate covering the period from January 4, 1994 to February 26, 1999 (1217 daily observations in total). US dollar is taken as the domestic currency. The US dollar interest rate is the one-month LIBOR converted to continuously compounded annual interest rate using the LIBOR convention. Since the data frequency is on the business day basis, we have for simplicity converted the annual continuously compounded rate to its daily equivalent by dividing 252. The Yen interest rate is the one-month LIBOR undergoing the same conversion as for the dollar LIBOR, which is used as the foreign interest rate in our model. To simplify the estimation we set the two risk premium parameters and the correlation constant.

The estimated parameter values and their respective sampling errors are reported in Table 1. It is clear from the table that the GARCH effect is significant for both the exchange rate and the 
Nikkei 225 return dynamics. The GARCH asymmetry parameter for the Nikkei 225 index return, i.e., $b$, turns out to be significantly positive, which suggests the leverage effect and is consistent with the finding for stock market indices. As to the exchange rate dynamic, the GARCH asymmetry parameter, i.e., $a$, is significantly negative. Note that the sign of $a$ will be reversed if the exchange rate is defined as Yen/US\$ instead. According to our definition, a negative value for $a$ suggests that the increase in the exchange rate volatility will be relatively stronger when Yen appreciates than when it depreciates.

The estimates for the exchange rate risk premium, $\delta$, the Nikkei 225 index risk premium, $\lambda$, and the correlation, $\rho$, are statistically insignificant. In our numerical analysis, these three parameter values are set to zero, i.e., $\delta=0, \lambda=0$ and $\rho=0$, unless otherwise stated. ${ }^{3}$ For option valuation, we set both the domestic and foreign interest rates constant so that the standard pricing formulas in the Black-Scholes framework can be used to obtain implied volatilities. Furthermore, to make the interpretation easier we set both rates at $0.0 \%$.

Before reporting the numerical results, some general discussions are in order. In our model, the unconditional return for both the exchange rate and the stock index is leptokurtic under the data generating measure $P$. Under the locally risk-neutralized measure $Q_{d}$, the returns continue to be leptokurtic, and the locally risk-neutralized return distributions have a negative (positive) skewness if the sum of the unit risk premium and the asymmetry parameter is positive (negative). The extent of skewness depends on the magnitude of the sum. Leptokurtosis tends to make an out-of-the-money or in-the-money option worth more than its constant-variance counterpart if there is no skewness under $\mathrm{Q}_{\mathrm{d}}$. Positive skewness under measure $\mathrm{Q}_{\mathrm{d}}$, however, tends to cause the constant-volatility model to underprice out-of-the-money call options. These two factors together determine the properties of the GARCH-based currency option pricing model.

In our setup, the extent of skewness and leptokurtosis for each of the processes is affected by all the GARCH parameters other than the constant portion of the variances, $\alpha_{0}$ and $\beta_{0}$. Under measure $\mathrm{Q}_{\mathrm{d}}$, the determining factors for the foreign exchange process are $\alpha_{1}, \alpha_{2}, a$, and $\delta$; and for the stock index process, they are $\beta_{1}, \beta_{2}, b, \lambda$, and $\rho$. $((\delta+a)$ and $(\lambda+b)$ enter the pricing model as a single parameter, as mentioned before.) In nature the effect of $\rho$ is similar to that of the sum,

3 . It is apparent from (2) and (5) that $(\delta+a)$ and $(\lambda+b)$ enter the pricing as a single parameter. Therefore there will be no loss of generality by setting $\delta$ and $\lambda$ to zero as long as the impact of $a$ and $b$ is examined, which we do. 
$\lambda+b$. However, as apparent in (5), the impact is stochastic due to the dependence on the exchange rate process. Relatively speaking, the sum of the risk premium and the asymmetry parameter will exert a much more manifest impact on the skewness and leptokurtosis than the correlation term. It can be shown (rf. Appendix of Duan (1995)) that a larger sum of the risk premium and the asymmetry parameter (regardless of its sign) will lead to a bigger leptokurtosis. Although a larger sum will also lead to a more manifest skewness as mentioned earlier, the sign of skewness will depend on the sign of the sum. Therefore, in an option pricing context the skewness and leptokurtosis effects are compounded or offset depending on the parameter combination and option's

moneyness. As for the coefficients, $\alpha_{1}, \alpha_{2}$ (or $\beta_{1}, \beta_{2}$ ), it can be shown (rf. Appendix of Duan (1995)) that they don't affect skewness, and that an increase in $\alpha_{1}$ (or $\beta_{1}$ ) while keeping stationary variance constant (by lowing $\alpha_{2}\left(\right.$ or $\beta_{2}$ )) will lead to a more pronounced leptokurtosis. The above general results are borne out by our numerical results to which we now turn.

\subsection{FX Options}

Previous studies which examine the performance of Black-Scholes type FX option pricing models have come to a consensus that the constant volatility, lognormal pricing model cannot explain the patterns observed in FX option prices. For example, Shastri and Wethyavivorn (1987) found that the average implied volatilities of five major currencies are roughly a U-shaped function of the ratio of the exercise price to the spot exchange rate. Using a similar data set spanning a slightly longer period, Bodurtha and Courtadon (1987) found that the constant-volatility American option pricing model underprices out-of-the-money options relative to at-the-money and in-the-money options. More recently, Bates (1996a) examined whether the Black-Scholes lognormal assumption deviates from the actual distributions of Deutsche mark and the Japanese yen. He found substantial (positive) skewness and excess kurtosis, at least for Deutsche mark. He also found that the distribution is not stable over time. For example, the Deutsche mark exhibits substantially positive skewness during 1984 to 1985 and a non-stable skewness thereafter. In a subsequent article, Bates (1996b) formulated a pricing model with jump diffusion processes and re-examined the Deutsche mark options. He concluded that modelling stochastic volatility using diffusion processes is not adequate, and it is necessary to incorporate jumps in order to explain the excess kurtosis.

We now study whether our GARCH framework can conveniently accommodate the empirical 
regularities in the FX options market. FX option prices are first computed under the GARCH specification together with the parameter estimates in Table 1, and then inverted using the constantvolatility model (e.g., Garman and Kohlgahen (1983)) to obtain the implied volatilities. These implied volatilities are plotted against the moneyness K/e. The GARCH option prices are calculated by Monte Carlo simulations according to (2). ${ }^{4}$ Calculations are done for options with different maturities ( $\mathrm{T}=20,60,120$, and 360 days $)$ and degrees of moneyness $(\mathrm{K} / \mathrm{e}=0.85,0.90,0.95,1.00$, $1.05,1.10$, and 1.15). For each maturity and moneyness combination we calculate three sets of prices and hence implied volatilities, each with a different level of initial conditional volatility (low initial variance: $\sqrt{ } \mathrm{q}_{1} / \sigma_{\mathrm{e}}=0.75$, average initial variance: $\sqrt{ } \mathrm{q}_{1} / \sigma_{\mathrm{e}}=1.0$, and high initial variance: $\left.\sqrt{ } \mathrm{q}_{1} / \sigma_{\mathrm{e}}=1.25\right)$. The unconditional volatility under measure $\mathrm{P}, \sigma_{\mathrm{e}}$, is calculated to be 0.144818 using the parameter values in Table 1 and assuming 252 days in a year.

The results of our numerical analyses are discussed below and partially presented in Figures 1,2 , and 3. ${ }^{5}$

Figures 1, 2, and 3 here

Figure 1 is based on GARCH parameters in Table 1. As expected, the negative asymmetry parameter $(a=-0.9637)$ leads to a positive skewness. Given a stationary volatility of 0.144818 , it can be seen from the figure that the constant variance model underprices out-of-the-money calls and overprice in-the-money calls. (The neutral point is slightly out-of-the-money, instead of at K/e =1.0 due to skewness.) For out-of-the-money options the skewness effect and the leptokurtosis effect reinforce each other, leading to underpricing by the constant variance model; for in-the-money options, the skewness effect (overpricing) dominates the leptokurtosis effect (underpricing). The shorter the maturity, the more manifest the results. The above observations are consistent with the

\footnotetext{
4. All prices are simulated with 50,000 runs each. To reduce variances, we use a combination of stratified simulations, a control variate, and the Empirical Martingale Simulations by Duan and Simonato (1998). Alternative numerical procedures have been proposed recently by various authors. For example, Duan, Gauthier and Simonato (1998) propose an analytical approximation procedure whereby European options under GARCH can be priced by matching moments of the return distribution; Duan and Simonato (1999) use a Markov chain to approximate the GARCH innovations and price options accordingly; and finally, Ritchken and Trevor (1999) develop a lattice framework for most univariate GARCH processes.

5. Figures 1, 2 and 3 are for the cases where the initial conditional variance is equal to the unconditional variance, $\sqrt{ } \mathrm{q}_{1} / \sigma_{\mathrm{e}}=1.0$. We omit the implied volatility plots under the other two scenarios (i.e. high and low initial variance) since qualitatively they do not add more insights other than the obvious. (For example, we will observe that a constant variance model will underprice options when the initial variance for GARCH is high, and vice versa.) We will also omit such scenarios later for the quanto options.
} 
findings in Bodurtha and Courtadon (1987), Bates (1996a) and Bates (1996b).

To demonstrate the impact of the asymmetry parameter on skewness and leptokurtosis, we re-run simulations by setting $a$ at -0.4 and 0.0 respectively, and the results are plotted in Figures 2 and 3. (We adjust $\alpha_{0}$ so that the stationary volatility remains at 0.144818 .) When $a=-0.4$ out-ofthe-money options are still underpriced, but some of the in-the-money options, i.e. options with $\mathrm{T}=20$ days, are also underpriced now, and the overall overpricing of the in-the-money options is less severe. This confirms our general predictions in that a reduction in the asymmetry parameter will make both the skewness and the leptokurtosis milder. A milder leptokurtosis is especially apparent in the lower implied volatilities for out-of-the-money options.

When $a$ is set to zero in Figure 3, the volatility curves become symmetrical smiles (centered at $\mathrm{K} / \mathrm{e}=1.0$ ), because skewness is completely absent now. In this case, it is seen that a constant variance model will underprice away-from-the-money options and overprice at-the-money short term options. This result is broadly consistent with the empirical findings by Shastri and Wethyavivorn (1987) and Taylor and Xu (1994). ${ }^{6}$

Incidentally, for out-of-the-money options, regardless of the extent of skewness, the implied volatility is a decreasing function of time to maturity. For near-the-money options, when skewness is absent or very mild, the implied volatility is an increasing function of time to maturity. All of the above are consistent with the empirical evidence in Shastri and Wethyavivorn (1987), who found that "for out-of-the-money, and deep-in-the-money options, implied volatilities decrease with increasing time to maturity, while the opposite holds for options that are close to at-the-money".

Finally, some recent empirical results indicate a broader consistency between jumps and foreign exchange returns. (See for example, Bates (1996b).) Insofar as jumps generate "fat-tails" or leptokurtosis, our GARCH framework is potentially equivalent to a jump-diffusion setup. However, one must keep in mind that the former is discrete and the latter is continuous. Both can accommodate "fat-tail" behaviour. The question as to which model can best describe the FX return behaviour and hence lead to more accurate pricing can only be answered empirically. The topic is best left for a separate future research endeavour.

6 . Since their findings are consistent with a zero skewness, we can infer that the sum of the risk premium and asymmetry parameter for currencies in their sample periods must be insignificant. Interestingly, that is what we found in an early version of our paper for the Japanese yen for the sample period of April 1985 to December 1990. Therefore our results (previous and current) seem to support the findings by Bates (1996a). 


\subsection{Quanto Options}

Empirical studies of quanto option pricing are scanty. Dravid, Richardson and Sun (1993) examined the pricing of Nikkei index warrants (listed on the American Stock Exchange) in a constant-volatility framework and found that their model produces prices close to the market prices for Nikkei put warrants but not for call warrants. Wei (1995) evaluated the same constant-volatility pricing model using Nikkei put warrants listed on the Toronto Stock Exchange and found that the model tends to overprice put warrants. (By put-call parity, one can infer that the model would also overprice call warrants.) There is no study to date which examines the implied volatility for quanto options, or cross-currency options in general. The predictions presented in this section for the GARCH-based quanto option pricing model can thus be viewed as testable implications for future studies.

Based on the parameter values given earlier, the unconditional volatility, under the data generating probability measure, for the Nikkei index is $\sigma_{\mathrm{s}}=0.265367$ (annualized based on a 252day year). ( $\sigma_{\mathrm{e}}$ remains at 0.144818 .) The constant-variance version of the pricing model in Wei (1992) and Dravid, Richardson and Sun (1993) is used to obtain the implied volatility of the option's model price based on the GARCH specification. We also fix the exchange rate volatility at its stationary level (0.144818) and the correlation at the estimated value $(0.0){ }^{7}$

The GARCH quanto option prices are computed in a fashion similar to that in Section 4.1, except that we now use (2), (5) and (6) in simulations. As in Section 4.1, five different maturities ( $\mathrm{T}=20,60,120$, and 360 days), seven exercise prices $(\mathrm{K} / \mathrm{S}=0.85,0.90,0.95,1.00,1.05,1.10$ and 1.15), and three initial levels of conditional variance for Nikkei index returns are considered, although we only report the results for the scenario whereby the initial conditional variance is equal to the stationary variance. We again consider three levels of the asymmetry parameter. Plots are presented in Figures 4, 5 and 6.

Figures 4, 5, and 6 here

The general insights obtained for the FX options also apply here, except that the skewness is in the opposite direction. Here, the skewness effect and the leptokurtosis effect reinforce each other for in-the-money options. Notice that at the estimated asymmetry parameter level $(b=0.8567)$,

7 . When the correlation is zero, the stock index process and the foreign exchange rate process are independent. But when the correlation is not zero (which we will consider), the two processes must be simulated simultaneously. 
the implied volatility curves are all monotonic in the degree of moneyness, which is also true for the other two levels of the initial conditional variance (not reported here). The highly skewed implied volatility curves for equity index options have been empirically observed by Canina and Figlewski (1993) for the S\&P 100 index options, by Rubinstein (1994) for the S\&P 500 index options, and by Duan (1996) for the FT-SE 100 index options. It can also be observed that the constant volatility pricing model of Wei (1992) and Dravid, Richardson and Sun (1993) can lead to sizable pricing errors if the true price dynamics follow the GARCH model.

As mentioned before, the conditional correlation affects the stock index return innovation in a complex fashion. To gain some insights into its impact, we repeat the calculations pertaining to Figures 4, 5, and 6 by varying the correlation level. It turns out that the marginal impact of correlation is quite similar for different levels of the asymmetry parameter and time to maturity. As a result, we only report results for one maturity, $T=120$ days in Figure 7 .

Figure 7 here

It is seen that the conditional correlation does not fundamentally alter the pattern of the volatility smile or "smirk", although it does affect the level of implied volatility for in-the-money options. Specifically, as the correlation moves away from zero, a higher negative correlation reduces the implied volatility, and a higher positive correlation increases the volatility, which is to say that an increase in the conditional correlation in general will manifest both the skewness and the leptokurtosis. (This can be understood by examining the variance innovation process in (5).) Given the almost identical implied volatilities for out-of-the-money options, we can infer that the conditional correlation mostly impacts the skewness and its effect on leptokurtosis is minimal. It is interesting to note that in pricing terms, a quanto call option's value is inversely related to correlation, especially for in-the-money options. (This is shown in Wei (1997) for the constant variance case.) For instance, in Figure 7, the option is worth the most when the correlation is -0.6.

So far, we have not been able to completely separate the skewness and leptokurtosis effects. However, it can be shown that when the stationary variance is kept constant, an increase in the coefficient $\alpha_{1}$ (or $\beta_{1}$ ) will leave the skewness unchanged (for a fixed asymmetry parameter) but lead to more leptokurtic returns. ( $\alpha_{2}$ or $\beta_{2}$ will have to be reduced accordingly to maintain the same stationary variance.) Different indexes can have different conditional variance innovations as 
presented by Heynen and Kat (1994), it is therefore of interest to see how the relative redistribution of weights of the two variance innovation parameters would affect the implied volatility profiles through leptokurtosis effects. To this end, we fix the asymmetry parameter at 0.4 and re-do the plots for different combinations of the two coefficients, $\beta_{1}$ and $\beta_{2}$ for the index. We report in Figure 8 implied volatilities for a time to maturity of 60 days. ${ }^{8}$

Figure 8 here

The increasing leptokurtosis as $\beta_{1}$ increases is quite evident in the plots. When $\beta_{1}$ is 0.02 , the implied volatility is virtually flat, which makes sense because the variance is almost constant in such a case, albeit a mild skewness still prevails. But as $\beta_{1}$ increases, a smile emerges, and the smile can be quite "wide". For instance, when $\beta_{1}$ is 0.32 , the lowest implied volatility is around $19 \%$, yet that for the deep-in-the-money option is higher than $28 \%$. This implies that when the empirical value of $\beta_{1}$ (which governs the random innovation of the conditional variance) is high a constant variance model could potentially produce a large pricing error. In addition, the plots clearly indicate that the potential contribution to skewness by the leverage parameter must be viewed in conjunction with the parameter, $\beta_{1}$.

\section{Conclusions}

In this paper we generalize the GARCH option pricing framework of Duan (1995) to a two-country setting. We assume a bivariate nonlinear asymmetric $\operatorname{GARCH}(1,1)$ model for the exchange rate and the foreign asset price. We then identify a locally risk-neutralized pricing measure for the domestic economy, and derive the exchange rate and foreign asset price dynamics with respect to this measure. As a result, foreign currency options and different types of cross-currency options, or options on foreign assets can be valued in this framework. The model can be readily generalized to a bivariate $\operatorname{GARCH}(\mathrm{p}, \mathrm{q})$ framework, which, for example, contains the GARCH-component model recently used by Engle and Rosenberg (1995) in their hedging analysis.

Our setup can accommodate most observed empirical regularities of exchange rates and stock

${ }^{8}$. We report only the results for an asymmetry parameter of 0.4 because it best illustrates the effect. When the asymmetry parameter is high, the skewness effect will be too strong, which will mask some of the leptokurtosis effect. Similarly, we choose a maturity of 60 days also for best illustration. All our conclusions remain valid for other parameter combinations. 
prices; for example, it allows a correlation between the conditional variance and the lagged returns for both the exchange rate and the stock price. This is especially useful for the stock price considering the existence of a negative correlation observed with many stocks (see, e.g., Black (1976) and Christie (1982)). Simulations show that our proposed GARCH pricing framework can accommodate the empirical evidence in the foreign exchange options markets.

The framework also allows flexible specifications of the conditional correlation. This flexibility is especially useful for studying specific effects of different model inputs. For example, we can specify different processes for the conditional correlation between the exchange rate and the foreign asset price to study the so-called "correlation risk" for cross-currency options, which has recently attracted much attention among academics and practitioners. Our proposed framework can be used to price other types of cross-currency options; for example, a derivative whose payoff is a direct function of the future exchange rate as well as the foreign stock price. For this type of crosscurrency options, the pricing errors of the constant-variance model is likely to be larger, and the use of the GARCH option pricing approach may prove to be even more relevant from a practical standpoint. 


\section{Appendix}

Proof of Proposition 2

Consider the return, measured in domestic currency, of investing in foreign stock. The cost at time $t$ is $S_{t} e_{t}$ and the gross return is $S_{t+1} e_{t+1}$ (cum dividends). By condition (iii) of the LRNVR,

$$
E^{Q_{d}}\left(\frac{S_{t+1} e_{t+1}}{S_{t} e_{t}} \mid \mathscr{F}_{t}\right)=\exp \left(r_{d, t+1}\right)
$$

Thus,

$$
1=\exp \left(\lambda_{t+1} \sqrt{h_{t+1}}+\delta_{t+1} \sqrt{q_{t+1}}-\frac{1}{2} h_{t+1}-\frac{1}{2} q_{t+1}\right) E^{Q_{d}}\left[\exp \left(\sqrt{h_{t+1}} \xi_{t+1}+\sqrt{q_{t+1}} \varepsilon_{t+1}\right) \mid \mathscr{F}_{t}\right] .
$$

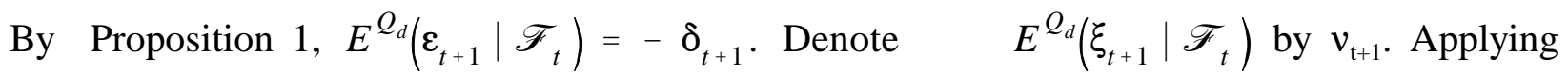
conditions (ii) and (iv) of the LRNVR yields

$$
\begin{aligned}
& E^{Q_{d}}\left[\exp \left(\sqrt{h_{t+1}} \xi_{t+1}+\sqrt{q_{t+1}} \varepsilon_{t+1}\right) \mid \mathscr{T}_{t}\right] \\
& \quad=\exp \left[\frac{1}{2} \operatorname{Var}^{P}\left(\sqrt{h_{t+1}} \xi_{t+1}+\sqrt{q_{t+1}} \varepsilon_{t+1} \mid \mathscr{T}_{t}\right)+\sqrt{h_{t+1}} v_{t+1}-\sqrt{q_{t+1}} \delta_{t+1}\right] \\
& \quad=\exp \left[\frac{1}{2}\left(h_{t+1}+q_{t+1}+2 \rho_{t+1} \sqrt{h_{t+1} q_{t+1}}\right)+\sqrt{h_{t+1}} v_{t+1}-\sqrt{q_{t+1}} \delta_{t+1}\right]
\end{aligned}
$$

We now have

$$
1=\exp \left[\sqrt{h_{t+1}}\left(\lambda_{t+1}+v_{t+1}+\sqrt{q_{t+1}} \rho_{t+1}\right)\right]
$$

which implies

$$
v_{t+1}=-\lambda_{t+1}-\sqrt{q_{t+1}} \rho_{t+1} .
$$

Since, by condition (iv) of the LRNVR,

$$
\operatorname{Var}^{Q_{d}}\left(\sqrt{h_{t+1}} \xi_{t+1}+\sqrt{q_{t+1}} \varepsilon_{t+1} \mid \mathscr{F}_{t}\right)=\operatorname{Var}^{P}\left(\sqrt{h_{t+1}} \xi_{t+1}+\sqrt{q_{t+1}} \varepsilon_{t+1} \mid \mathscr{F}_{t}\right),
$$


we must have

$$
\begin{gathered}
h_{t+1} \operatorname{Var}^{Q_{d}}\left(\xi_{t+1} \mid \mathscr{F}_{t}\right)+q_{t+1} \operatorname{Var}^{Q_{d}}\left(\varepsilon_{t+1} \mid \mathscr{F}_{t}\right)+2 \sqrt{h_{t+1} q_{t+1}} \operatorname{Cov}^{Q_{d}}\left(\xi_{t+1}, \varepsilon_{t+1} \mid \mathscr{F}_{t}\right) \\
=h_{t+1}+q_{t+1}+2 \sqrt{h_{t+1} q_{t+1}} \rho_{t+1} .
\end{gathered}
$$

Because $\operatorname{Var}^{Q_{d}}\left(\varepsilon_{t+1} \mid \mathscr{F}_{t}\right)=1$ by Proposition 1, it must be

$$
\operatorname{Var}^{Q_{d}}\left(\xi_{t+1} \mid \mathscr{F}_{t}\right)=1 \text { and } \operatorname{Cov}^{Q_{d}}\left(\xi_{t+1}, \varepsilon_{t+1} \mid \mathscr{F}_{t}\right)=\rho_{t+1} \text {, }
$$

which in turn implies

$$
E^{Q_{d}}\left(\xi_{t+1}^{*} \varepsilon_{t+1}^{*} \mid \mathscr{F}_{t}\right)=\operatorname{Cov}^{Q_{d}}\left(\xi_{t+1}^{*}, \varepsilon_{t+1}^{*} \mid \mathscr{F}_{t}\right)=\operatorname{Cov}^{Q_{d}}\left(\xi_{t+1}, \varepsilon_{t+1} \mid \mathscr{F}_{t}\right)=\rho_{t+1} .
$$

Substituting $\xi_{t+1}^{*}$ into (6) completes the proof.

Q.E.D. 


\section{References}

Amin, K. and V. Ng, 1993, ARCH Processes and Option Valuation, unpublished manuscript, University of Michigan.

Bates, David S., 1996a, Dollar Jump Fears, 1984-1992: Distributional Abnormalities Implicit in Currency Futures Options, Journal of International Money and Finance, 15(1), 65-93.

Bates, David S., 1996b, Jumps and Stochastic Volatility: Exchange Rate Processes Implicit in Deutsche Mark Options, Review of Financial Studies, 9(1), 69-107.

Biger, N. and John Hull, 1983, The Valuation of Currency Options, Financial Management, 12, 2428.

Black, Fischer, 1976, Studies in Stock Price Volatility Changes, Proceedings of the 1976 Meeting of the Business and Economic Statistics Section, American Statistical Association, 177-181.

Bodurtha, James. and George Courtadon, 1987, Tests of an American Option Pricing Model on the Foreign Currency Option Market, Journal of Financial and Quantitative Analysis, 22(2), 153-167.

Bollerslev, Tim, 1986, Generalized Autoregressive Conditional Heteroscedasticity, Journal of Econometrics 31, 307-327.

Bollerslev, T,, R. Chou, and K. Kroner, 1992, ARCH Modeling in Finance: A Review of the Theory and Empirical Evidence, Journal of Econometrics 52, 5-59.

Canina, Linda and Stephen Figlewski, 1993, The Information Content of Implied Volatility, Review of Financial Studies, 6(3), 659-681.

Chaudhury, Mohammed M. and Jason Z. Wei, 1996, A Comparative Study of the $\operatorname{GARCH}(1,1)$ and Black-Scholes Option Prices, Working Paper, University of Saskatchewan.

Christie, Andrew A., 1982, The Stochastic Behaviour of Common Stock Variances: Value, Leverage and Interest Rate Effects, Journal of Financial Economics 10, 407-432.

Day, Theodore E. and Craig M. Lewis, 1992, Stock Market Volatility and the Information Content of Stock Index Options, Journal of Econometrics 52, 267-287.

Dravid, A., M. Richardson and T. Son, 1993, Pricing Foreign Index Contingent Claims: An Application to Nikkei Put Warrants, The Journal of Derivatives 1, 33-51.

Duan, J.-C., 1995, The GARCH Option Pricing Model, Mathematical Finance 5(1), 13-32. 
Duan, J.-C., 1996, Cracking the Smile, Risk 9 (December), 55-59.

Duan, J.-C., 1997, Augmented GARCH(p,q) Process and its Diffusion Limit, Journal of Econometrics, 79, 97-127.

Duan, J.-C. and Jean-Guy Simonato, 1998, Empirical Martingale Simulation for Asset Prices, Management Science, 44, 1218-1233.

Duan, J.-C., G. Gauthier and J.G. Simonato, 1998, An Analytical Approximation for the GARCH Option Pricing Model, Working paper, Hong Kong University of Science and Technology.

Duan, J.-C. and J.G. Simonato, 1999, American Option Pricing under GARCH by a Markov Chain Approximation, Working paper, Hong Kong University of Science and Technology.

Engle, Robert F., 1982, Autoregressive Conditional Heteroscedasticity with Estimates of the variance of U.K. Inflation, Econometrica 50, 987-1008.

Engle, Robert F. and Chowdhury Mustafa, 1992, Implied ARCH Models from Options Prices, Journal of Econometrics 52, 289-311.

Engle, Robert F. and Joshua V. Rosenberg, 1995, GARCH Gamma, Journal of Derivatives, Vol 2, No. 4, 47-59.

Garman, Mark and S. Kolhagen, 1983, Foreign Currency Option Values, Journal of International Money and Finance, 2, 231-238.

Gruca, E. and P. Ritchken, 1993, Exchange Traded Foreign Warrants, Advances in Futures and Options Research 6, 53-66.

Heynen, Ronald and Harry Kat, 1994, Volatility Prediction: A Comparison of the Stochastic Volatility, GARCH(1, 1), and EGARCH(1,1) Models, Journal of Derivatives, Vol 2(2), 50-65.

Heynen, Ronald, Angelien Kemna and Ton Vorst, 1994, Analysis of the Term Structure of Implied Volatilities, Journal of Financial and Quantitative Analysis, 29 (1), 31-56.

Nelson, Daniel B., 1990, Stationarity and Persistence in the GARCH(1, 1) Model, Econometric Theory 6, 318-334.

Noh, Jaesun, Robert F. Engle and Alex Kane, 1994, Forecasting Volatility and Option Prices of the S \& P 500 Index, Journal of Derivatives 2(1), 17-30.

Ritchken, Peter and Rob Trevor, 1999, Pricing Options under Generalized GARCH and Stochastic Volatility Processes, Journal of Finance, 54(1), 377-402. 
Rubinstein, Mark, 1994, Presidential Address: Implied Binomial Trees, Journal of Finance, 49(3), 771-818.

Shastri, Kuldeep and Kulpatra Wethyavivorn, 1987, The Valuation of Currency Options for Alternate Stochastic Processes, Journal of Financial Research, 10(2), 283-293.

Taylor, Stephen J., 1986, Modelling Financial Time Series, Wiley, New York, NY.

Taylor, Stephen J. and X. Xu, 1994, The Magnitude of Implied Volatility Smiles: Theory and Empirical Evidence for Exchange Rates, The Review of Futures Markets, 13(2), 355-380.

Wei, Jason Z., 1992, Pricing Nikkei Put Warrants, Journal of Multinational Financial Management 2(2), 45-75.

Wei, Jason Z., 1995, Empirical Tests of the Pricing of Nikkei Put Warrants, Financial Review, Vol 30, No 2, 211-241.

Wei, Jason Z., 1997, Valuing Derivatives Linked to Foreign Assets, in Frontiers in Derivatives, edited by Atsuo Konishi and Ravi E. Dattatreya, Irwin Professional Publishing. 
Table 1. Parameter estimates and sampling standard errors for the joint dynamics of the US\$/Yen exchange rate and the Nikkei 225 index (daily) from January 4, 1994 to February 26, 1999.

\begin{tabular}{|ccc|}
\hline & Parameter estimates & $\begin{array}{c}\text { Sampling standard } \\
\text { errors }\end{array}$ \\
\hline $\begin{array}{c}\text { Exchange rate } \\
\text { process } \\
\text { parameters }\end{array}$ & \\
\hline$\alpha_{0}$ & 0.0000188272 & 0.0000019300 \\
$\alpha_{1}$ & 0.1736645722 & 0.0193642271 \\
$\alpha_{2}$ & 0.4388191542 & 0.0441675590 \\
$a$ & -0.9637127481 & 0.1006403905 \\
$\delta$ & -0.0258114411 & 0.0305670171 \\
\hline Stock index & & \\
process & & \\
parameters & & 0.0000007712 \\
\hline$\beta_{0}$ & 0.0000037719 & 0.0123314186 \\
$\beta_{1}$ & 0.0779830853 & 0.0146376825 \\
$\beta_{2}$ & 0.8512878498 & 0.1081513698 \\
$b$ & 0.8566744666 & 0.0291629205 \\
$\lambda$ & -0.0215612474 & \\
\hline Correlation & & 0.0244170073 \\
\hline$\rho$ & -0.0192223444 & \\
\hline Log-likelihood & 9914.6730606 & \\
\hline Sample Size & 1217 & \\
\hline & & \\
\hline
\end{tabular}

Note that the estimates for the two risk premium parameters and the correlation are not statistically significant. Unless otherwise stated we set them to zero for numerical analysis in Section 4. 
Figure 1. Implied Volatility vs. Moneyness for FX Call Option Prices under GARCH - High Positive Skewness, $\mathrm{a}=-0.9637-$

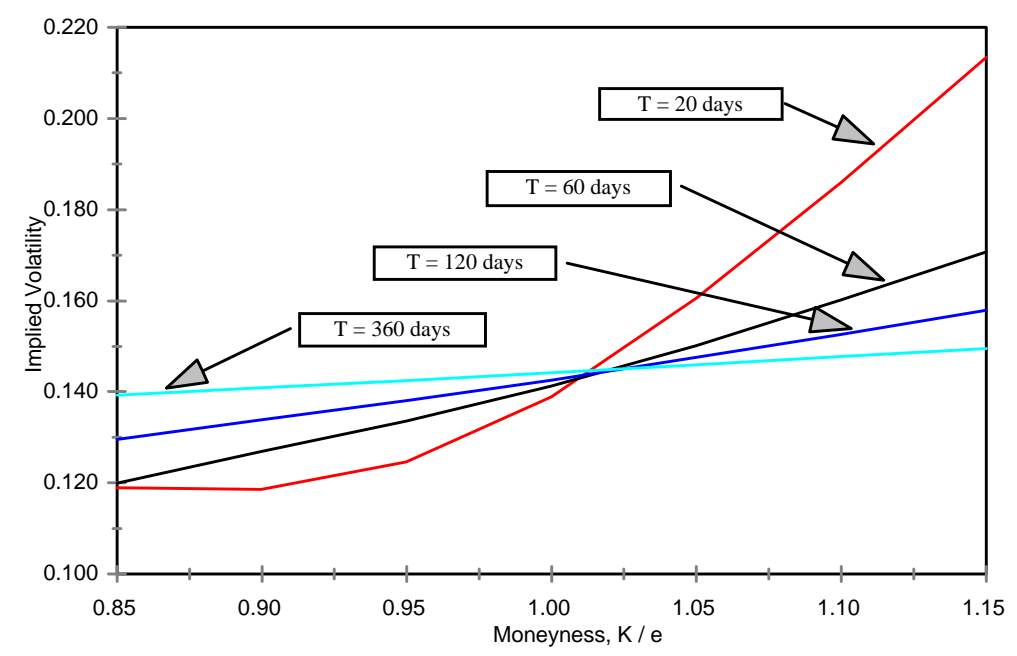

Figure 2. Implied Volatility vs. Moneyness for FX Call Option Prices under GARCH - Medium Positive Skewness, $a=-0.4000-$

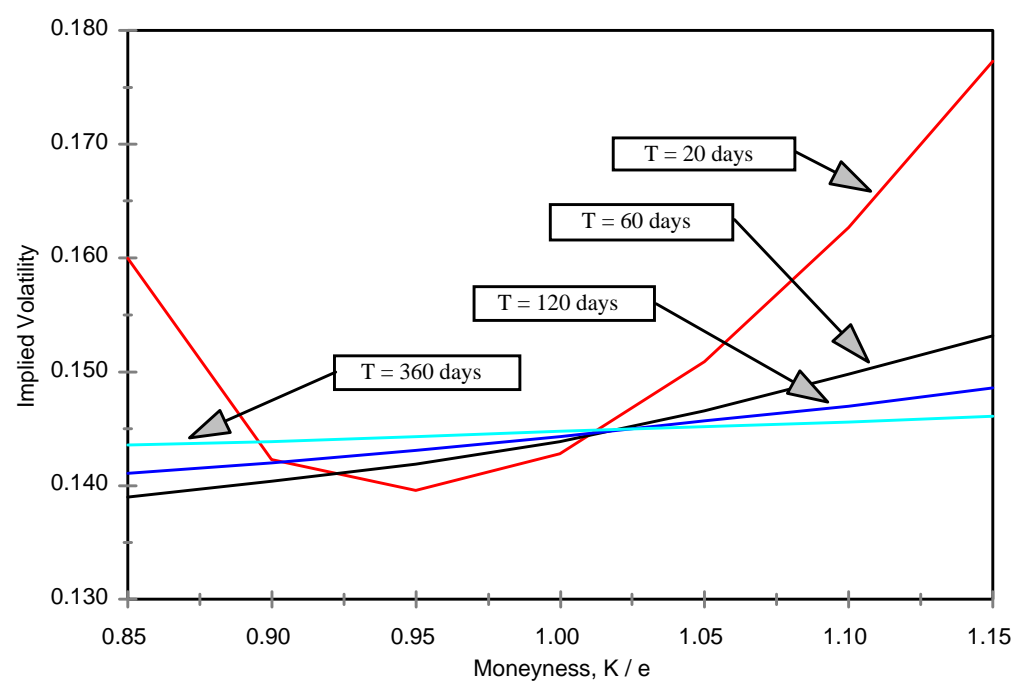

Figure 3. Implied Volatility vs. Moneyness for FX Call Option Prices under GARCH - Zero Skewness, $a=0.0000-$

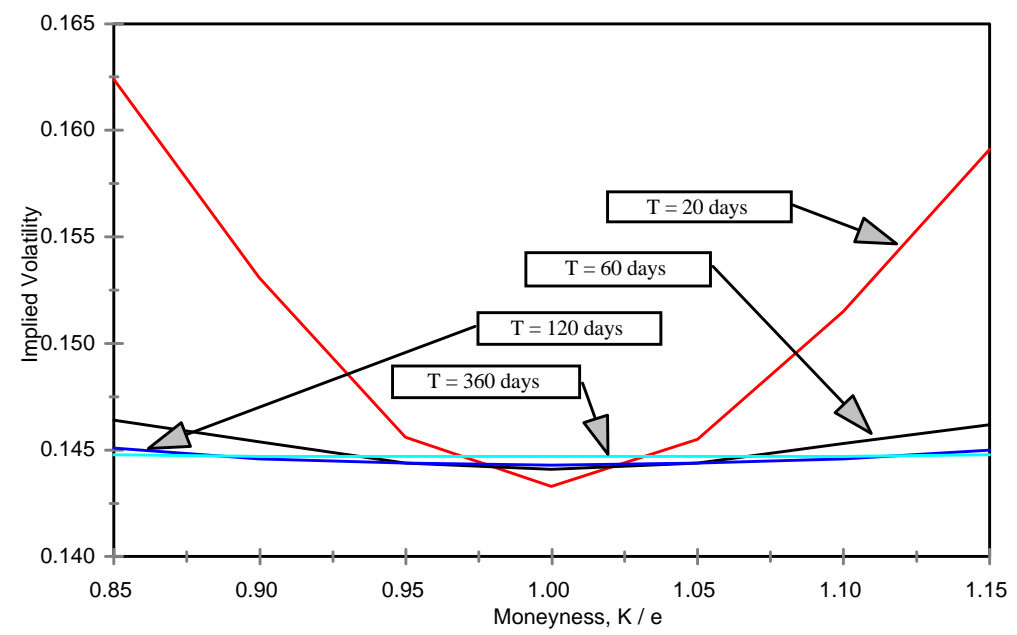


Figure 4. Implied Volatility vs. Moneyness for Quanto Call Option Prices under GARCH - High Negative Skewness, $b=0.8567$ -

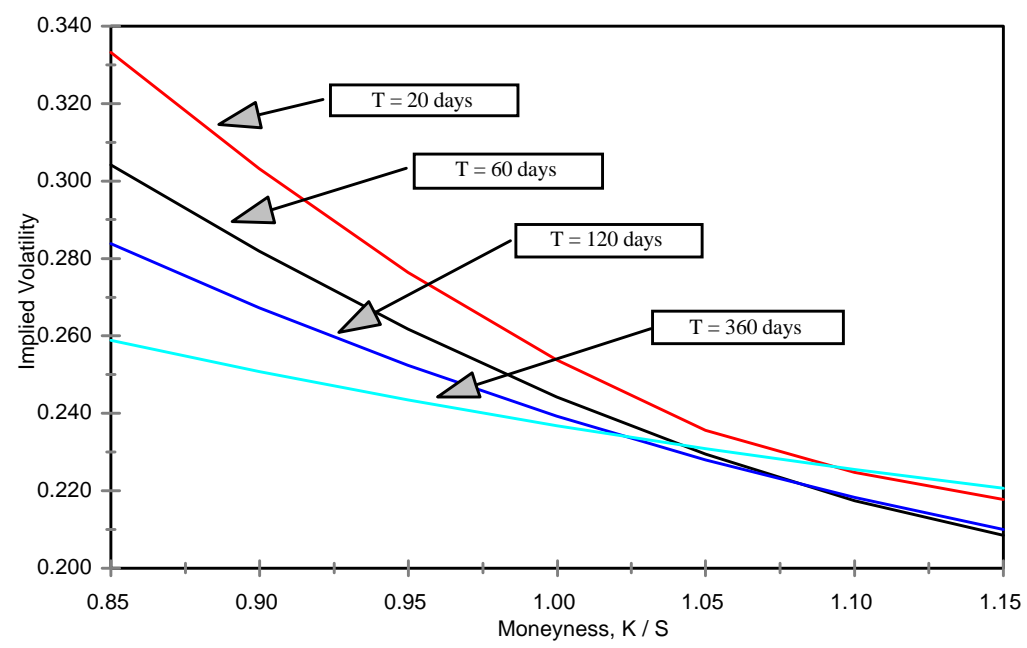

Figure 5. Implied Volatility vs. Moneyness for Quanto Call Option Prices under GARCH - Medium Negative Skewness, $b=0.4000-$

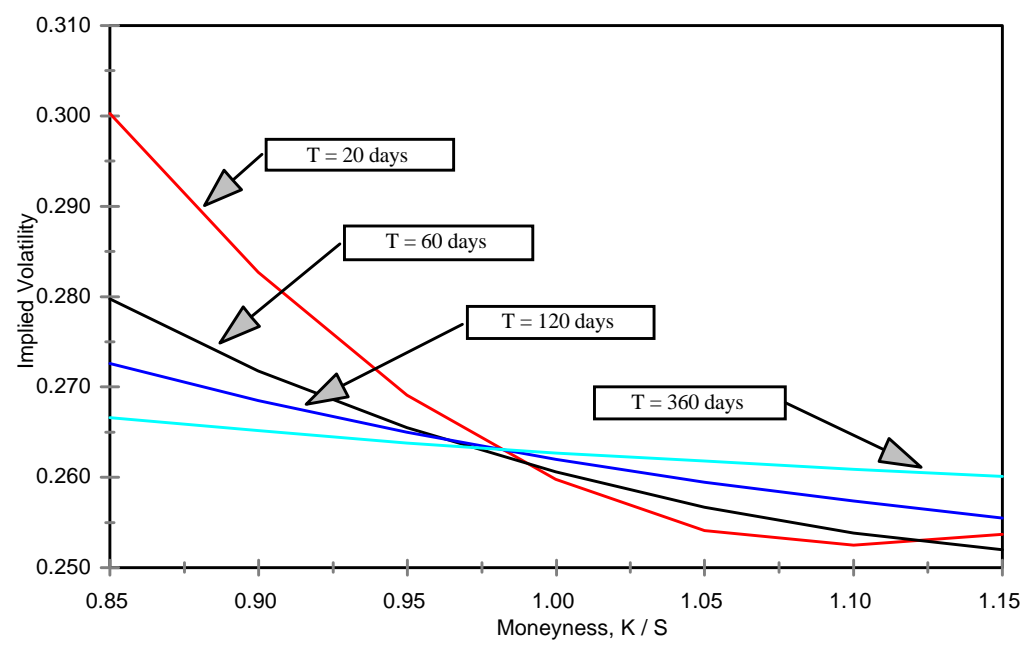

Figure 6. Implied Volatility vs. Moneyness for Quanto Call Option Prices under GARCH - Zero Skewness, $b=0.0000-$

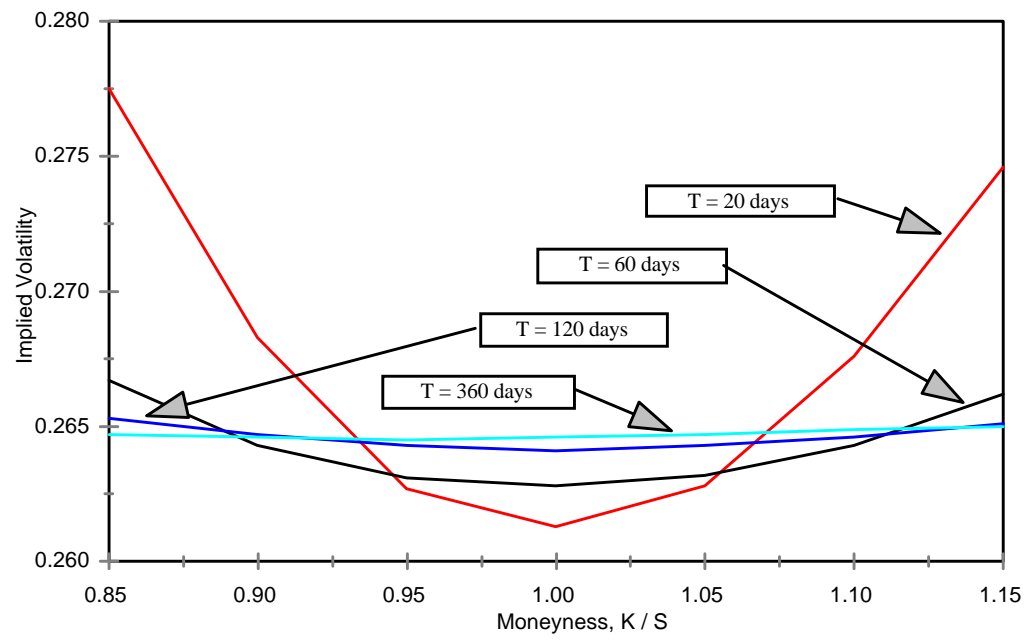


Figure 7. Impact of Correlation on Implied Volatility for Quanto Call Option Prices - Time to Maturity = 120 days -

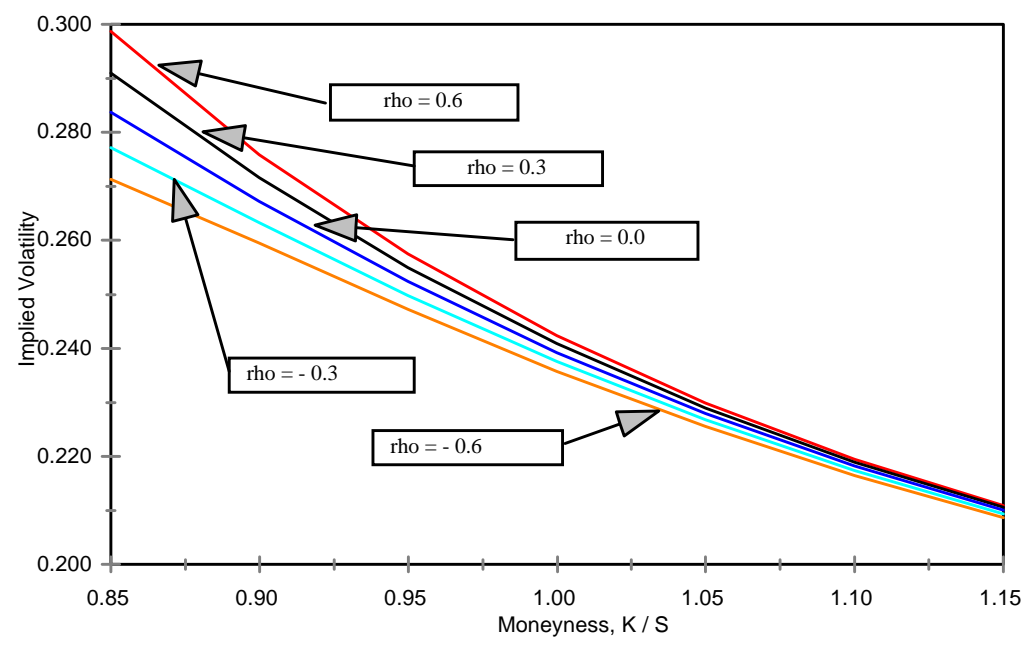

Figure 8. Impact of GARCH Innovation on Implied Volatility for Quanto Call Option Prices - Time to Maturity $=60$ days, Leverage Parameter $=0.4$

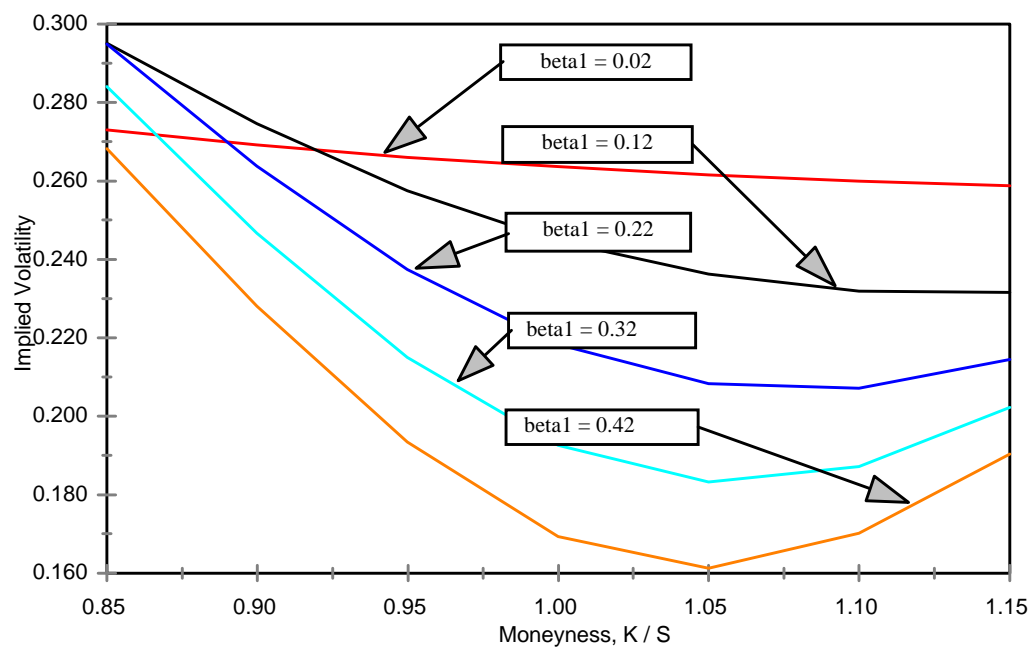

(The two innovation coefficients, $\beta_{1}$ and $\beta_{2}$ are varied such that the stationary variance under measure $P$ remains at 0.2654 for an asymmetry parameter of $\mathrm{b}=0.4$. Specific combinations are,

$$
\begin{aligned}
& \beta_{1}=0.02, \beta_{2}=0.963302, \\
& \beta_{1}=0.12, \beta_{2}=0.847302, \\
& \beta_{1}=0.22, \beta_{2}=0.731302, \\
& \beta_{1}=0.32, \beta_{2}=0.615302, \\
& \left.\beta_{1}=0.42, \beta_{2}=0.499302 .\right)
\end{aligned}
$$

